\title{
Creating a successful name (based on psycholinguistic experiments)
}

\author{
Khurshida Zakirova ${ }^{1, *}$, Mariya Zakharova-Sarovskaya ${ }^{2}$, and Alexandra Zakharova $^{3}$ \\ ${ }^{1}$ Ufa State Petroleum Technological University, Branch of the University in the City of Oktyabrsky, 54a, Devonskaya St., \\ Oktyabrsky, Republic of Bashkortostan, 452607, Russia \\ ${ }^{2}$ Siberian State University of Geosystems and Technologies, 10, Plakhotny St., Novosibirsk, 630108, Russia \\ ${ }^{3}$ Novosibirsk State Technical University, 20, KarlMarks St., Novosibirsk, 630092, Russia
}

\begin{abstract}
On the basis of receptive and free association experiments were established peculiarities of perception of typical and creative names, the leading criteria for the recipients' perception were determined, and the criteria for evaluating a successful name were proposed. The identified criteria correlate with the principles and conditions for creating a successful name. Successful is the name, which, according to the results of the receptive experiment, assessed by the recipients in the positive part on most scales, while the motives, functions and purposes of the ergonym established at the generation stage, different for standard and non-standard names, are realized with the help of clear means of marking for native speakers of Russian; and according to the association analysis results, they contain semantic zones corresponding to the profile of the company activity and do not reveal sharply negative assessments and reactions associated with incomprehensibility.
\end{abstract}

\section{Introduction}

The generation of any name aims to attract the attention of potential customers and create a favorable impression of the company. At the same time, recently created multicomponent nominations with obscure or non-obvious semantics often make communication difficult. The need to establish conditions for creating successful names is crucial in the naming theory and communication theory.

Naming or synonymy is a "work package aimed at creating successful marketing names for brands and status company names. Naming is subordinated to goals and objectives of branding, depends on brand positioning, marketing, and future-oriented outlook management"

G. Charmesson in the study "Brand: How to create a name that will bring millions" [1] offers specific methods for creating successful and convincing names. Orientation to ready-made templates and patterns for creating names is reflected in the practice direction of $\mathrm{V}$. Pertsiya and L. Mamleyeva "Branding. The course of a young fighter" [2]. Naming is no longer creativity, but technology, a step-by-step method of creating a working brand.

The pragmatic approach with respect to names is the study of the linguistic manipulation of the nominator on the recipient through experiments and construction of theoretical generalizations based on them. To study success of nominations, a series of psycholinguistic experiments were conducted. Objective: based on data from receptive and association experiments, identify successful names and determine the most important criteria for the perception of composite recipients, by identifying.

The main purpose of ergonyms for creating names, according to naming, is commercial success in the market, a number of tasks are subordinate to this goal: the ability to stand out and occupy a special niche among competitors; strengthen the positioning; create positive associations with consumers for the long term; generate a memorable name; get an independent means of advertising; provide inspiration for numerous marketing companies; occupy a dominant position in the category [2]. Names that achieve the specified goals and objectives in translation literature on naming are usually called successful (from the English success), see, for example, [4].

To implement a successful name, it is important to establish popular traditional and creative methods, types and models of nomination, as well as rely on various methods for measuring perception of ergonyms.

In linguistics, the effect of names is studied in the aspect of pragmatics (I.V. Kryukova, M.G. Kurbanova, M.E. Novichikhina, N.V. Nosenko, E.A. Trifonova, T.V. Shmeleva, and others). In this study, under pragmatics, followed by I.P. Susov, we understand "the field of linguistic research, having as its object a relationship between language units and the conditions of their use in a certain communicative-pragmatic space in which the speaker/writer and the listener/reader interact and for whose characteristics specific indications of the place and time of their speech interactions related to the act of communicating goals and expectations." The impact

\footnotetext{
* Corresponding author: kh.zak62@mail.ru
} 
"cannot be considered successfully implemented if it does not lead to a certain result." In this connection, important research is identification of successful names that achieve the goals set by the nominee in generating the naming.

On the basis of surveys of recipients, the conditions for creating a successful ergonym were also developed. According to A.M. Yemelyanova, who studied the names in the rhetorical aspect, is the following conditions:

- Accounting for the AIDA scheme used in foreign advertising practice, which translates as "attention interest - desire - action", see, for example, [4]. Ergonym should attract attention and keep it through external and internal form; cause a desire to choose from a number of similar.

- Using a wide range of onym opportunities so that the name is not stereotypical, to mark its individuality, dissimilarity.

- Avoiding homonymy.

- Aestheticism, pronounceableness, harmonious naming.

- Compliance with the rules of the spelling of the modern Russian language.

- The absence of false associations, contrary to the type of activity of the enterprise.

- Accounting background knowledge of the nominator and potential customer. Any communication is impossible without correlation of knowledge of the informer and the receiving information.

- Use of native language tool.

- Reflection of the specifics of the region of the company activity.

- The sharing of common positive properties of a commercial enterprise.

- Development of potential assessment.

Naming specialists have developed various classifications of names, principles, and conditions for creating ergonyms, specific methods, and technologies for creating persuasive and successful names. Orientation to ready-made templates and samples for creating names is reflected in the practical recommendations of specialists in naming. As components of the proposed options in numerous online generators, frequency components are used that automatically join the base component, reflecting the company's business, and contribute to the productivity of composition as a way of forming company names.

Perception at the linguistic level occurs on the basis of the implementation of a complex of interrelated "linguistic" and "semantic" operations. Evaluation and understanding of the perceived message in accordance with the intended nominal of the nominator, its comprehensibility to the recipient are the result of the perception and characteristics of an ergonym as successful. The deciphering of the content laid down in a new word by a native speaker is successful if he knows the meanings of constituent components and semantic features that show the connection between them.

The result of perception of specific names is not always identical to the intended impact of the nominator and successfully implements the motive and certain functions laid down by the nominator. Therefore, it is important to establish perceived when decrypting the pledged internal content and acceptable for recipients' models, methods and techniques for the formation of names. It is also necessary to identify a list of criteria for creating a successful ergonym from the point of view of a recipient, corresponding to the motives, goals and principles used when generating a composite. A series of experiments were conducted to test the proposed assumption and solve the set goals.

The receptive experiment was based on the names on the scales described by $\mathrm{Ch}$. Osgood [6] from the studied groups of composites and was conducted in June-September 2018. The experiment participants were 146 students of Novosibirsk State Technical University and Siberian State University of Geosystems and Technologies. The age of students is $18-24$ years, the gender composition of participants is mixed. The experiment was conducted in the classroom study time, tasks were initially clarified by the experimenter, then in the online application form, students evaluated the items displayed on scales from -3 to +3 .

The selection of scales for the main stage was carried out by a group of linguists and teachers (in the amount of 23 people) who have experience in interpreting experimental data using the semantic differential method. Participants were offered a list of selected names for the experiment and 28 criteria for evaluating ergonyms. It was necessary to note the most appropriate criteria describing the perception of the presented company names.

The expert group chose the following 12 scales as relevant for assessing perception of ergonyms: unpleasant - pleasant, incomprehensible understandable, uninteresting - interesting, difficult simple, deceitful - honest, inappropriate - relevant, abstract - concrete, temporary - universal, useless useful, common - unique, rare - frequent, unacceptable acceptable.

The results of the pilot experiment are described in detail in the article [7].

To carry out a free association experiment (FAE), the same list of 29 stimuli was used as an experimental material as in the main stage of a receptive experiment. These are productive standard names: Audit-taxes-law, AIR-WATER, BusinessProfi, House-Dacha-Interior, E2E4, Evrodrova (euro firewood), HAPPY-IDEAS, Zapravka.online (Station.online), Furniture555, GRUZOPODYEMSPETSTEHNIKA-SIBIR (WEIGHT LIFTING SPECIAL VEHICLES-SIBERIA), little house154.rf; as well as non-typical, creative, different using non-standard (non-traditional) components and language game: Aytibay (ITbuy), BA! TUT! (trampoline), BLINCHEEK (LITTLE PANCAKE), BIZOVO.RU, Burbrigada (drilling-rig crew), VSEINSTRUMENTI.RU (ALL TOOLS.RU), ESLIPUSTO.RU (IF EMPTY.RU), Korsety\&Sorocki (Corsets\&Shirts), COPI.RUS, LINZITUT (LENSES HERE), Ellyuneslo (Fly Elly), PROSTOMASTER (JUST MASTER), NOL-BOL (ZeroPain), PROPRO GROUP, POLPOLPOL.RU (FLOOR.RU), Nanobanka (Nanobathhouse), AVTOOVCHINKA (AUTO-SHEEPSKIN), HAPPY-IDEAS. 
The experiment was conducted in May - September 2018. Composition of subjects and the experimental site of the experiment are the same as in the main stage of the receptive experiment.

The stimulus words were presented using Google questionnaires, the task was explained orally, the experiment was conducted in classrooms during class time, no refusals of participation were recorded. The subjects had to fill in the online forms for the answer by the first association to each name shown in turn. Lists of names for each subject were formed by the method of random numbers. Such a multivariate presentation of questionnaires eliminated the possibility of influencing the responses of previous stimuli on the composition of the association area (AA).

The data processing procedure: the construction of association areas (AA) according to the generally accepted method, as well as the construction of semantic gestalts according to the method developed by Yu.N. Karaulov. Semantic gestalt is based on the semantic classification of AA reactions. Its composition is determined by several semantic zones, which combine "the characteristics of an object or concept that are typical for a given language consciousness".

\section{Results and discussion}

\subsection{Receptive experiment data}

As a result of the receptive experiment, 50,808 reactions were obtained. The summary data obtained by adding the estimates for all the criteria for each name is presented in Table 1 . The names order in the table is arranged in accordance with the intensity of the estimates - from highest to lowest.

Table 1. Consolidated figures estimations on the scale for names.

\begin{tabular}{|l|c|c|}
\hline \multicolumn{3}{|c|}{ POSITIVE ESTIMATIONS (Group A1) } \\
\hline \multicolumn{1}{|c|}{ Company Names } & $\begin{array}{c}\text { Sum of } \\
\text { estimations }\end{array}$ & $\begin{array}{c}\text { Average } \\
\text { value }\end{array}$ \\
\hline $\begin{array}{l}\text { VSEINSTRUMENTI.RU (ALL } \\
\text { TOOLS.RU) }\end{array}$ & 13.22 & 1.101667 \\
\hline LINZI-TUT (LENSES HERE) & 12.27 & 1.0225 \\
\hline NOL-BOL (Zero-Pain) & 12.22 & 1.018333 \\
\hline BA! TUT! (trampoline) & 11.75 & 0.979167 \\
\hline COPI.RUS & 9.12 & 0.76 \\
\hline Audit-taxes-law & 9.04 & 0.753333 \\
\hline House-Dacha-Interior & 9.02 & 0.751667 \\
\hline BusinessProfi & 8.98 & 0.748333 \\
\hline HAPPY-IDEAS & 8.95 & 0.745833 \\
\hline Nanobanka (Nanobathhouse) & 8.21 & 0.684167 \\
\hline AIR-WATER & 7.57 & 0.630833 \\
\hline $\begin{array}{l}\text { PROSTOMASTER (JUST } \\
\text { MASTER) }\end{array}$ & 6.98 & 0.581667 \\
\hline Zapravka.online (Station.online) & 6.88 & 0.625455 \\
\hline
\end{tabular}

\begin{tabular}{|l|c|c|}
\hline Furniture555 & 6.24 & 0.52 \\
\hline little house154.rf & 5.96 & 0.496667 \\
\hline Evrodrova (euro firewood) & 5.92 & 0.493333 \\
\hline $\begin{array}{l}\text { BLINCHEEK (LITTLE } \\
\text { PANCAKE) }\end{array}$ & 5.26 & 0.438333 \\
\hline $\begin{array}{l}\text { Korsety\&Sorocki } \\
\text { (Corsets\&Shirts) }\end{array}$ & 4.7 & 0.391667 \\
\hline $\begin{array}{l}\text { GRUZOPODYEMSPETSTEHNI } \\
\text { SA-SIBIR (WEIGHT LIFTING } \\
\text { SPECIAL VEHICLES-SIBERIA) }\end{array}$ & 2.69 & 0.224167 \\
\hline \multicolumn{2}{|c|}{ NEGATIVE ESTIMATIONS (Group B1) } \\
\hline BIZOVO.RU & -9.81 & -1.50923 \\
\hline PROPRO GROUP & -8.87 & -0.73917 \\
\hline Ellyuneslo (Fly Elly) & -6.73 & -0.56083 \\
\hline ESLIPUSTO.RU (IF EMPTY.RU) & -6.05 & -0.93077 \\
\hline TVOI54.RU (YOUR54.RU) & -5.88 & -0.90462 \\
\hline POLPOLPOL.RU (FLOOR.RU) & -5 & -0.41667 \\
\hline Burbrigada (drilling-rig crew) & -4.81 & -0.40083 \\
\hline Aytibay (ITbuy) & -4.43 & -0.36917 \\
\hline E2E4 & -3.63 & -0.33 \\
\hline $\begin{array}{l}\text { AVTO-OVCHINKA (AUTO- } \\
\text { SHEEPSKIN) }\end{array}$ & -1.02 & -0.085 \\
\hline
\end{tabular}

The analysis of composite ergonyms revealed some regularities in the names:

a) The prevalence of negative estimations was noted in the following composite ergonyms:

- POLPOLPOL.RU (FLOOR.RU), Burbrigada (drilling-rig crew), BIZOVO.RU, TVOI54.RU (YOUR54.RU), AVTO-OVCHINKA (AUTOSHEEPSKIN), Aytibay (ITbuy), in which there is a substitution of writing Cyrillic script (for Russian or frequency and long-assimilated components such as Auto) to Latin or a reverse replacement from Latin writing to Cyrillic script (BIZOVO and Bay - from English BIZ and buy);

- For Russian names that have the incomprehensible activity area: PROPRO GROUP, Ellyuneslo (Fly Elly), ESLIPUSTO.RU (IF EMPTY.RU), E2E4.

b) Composites that have a negative total value by the sum of all criteria are included in the group of nonstandard ergonyms with the exception of abbreviation. Thus, a part of non-traditional names that use certain techniques and elements of the language game was rated negatively by the respondents.

c) The standard naming group is dominated by positive estimations. However, the results of the analysis of the highest aggregate indicators for the sum of all the estimation criteria (See Table 7) revealed a significant gap in the sum of the criteria for non-standard naming conventions: VSEINSTRUMENTI.RU (ALL TOOLS.RU), LINZI-TUT (LENSES HERE) (unsupervised adhesion models), NOL-BOL (Zero-Pain) (adhesion or attribute model of an analytical stem composition with rhyme) BA! TUT! (trampoline) (blend model). All names are formed with participation of Russian components without changing the graphics. 
Lower scores of the traditional group may be the result of uninteresting indicators correlating for this group.

d) The incomprehensibility of an ergonym entails a complex of other negative estimations. Incomprehensible names are also perceived as temporary, unpleasant, unacceptable, abstract, complex, useless. Falsity, and sometimes relevance and concreteness remain unexpressed with incomprehensible naming. (Burbrigada (drilling-rig crew), BIZOVO.RU, Ellyuneslo (Fly Elly), PROPRO GROUP, ESLIPUSTO.RU (IF EMPTY.RU)).

The name may be incomprehensible, but interesting (Ellyuneslo (Fly Elly)) or uninteresting (PROPRO Group).

e) On a scale that is complex - simple with respect to composites, the most antonymous pair can be interpreted in several ways. So, according to the recipients, the following names are difficult:

- BLINCHEEK (LITTLE PANCAKE), AVTOOVCHINKA (AUTO-SHEEPSKIN), Burbrigada (drilling-rig crew) (difficult for perception due to foreign language graphics);

- POLPOLPOL.RU (FLOOR.RU), TVOI54.RU (YOUR54.RU), Aytibay (ITbuy) (also rated as incomprehensible due to the change in the usual for the component of the display language); BIZOVO.RU, E2E4, ESLIPUSTO.RU (IF EMPTY.RU), Ellyuneslo (Fly Elly), PROPRO GROUP (as not reflecting the scope of activities); GRUZOPODYEMSPETSTEHNIKASIBIR (WEIGHT LIFTING SPECIAL VEHICLESSIBERIA), Korsety\&Sorocki (Corsets\&Shirts) (as complex in composition).

f) Trouble may occur due to additional associations. (BLINCHEEK (LITTLE PANCAKE), Burbrigada (drilling-rig crew), ESLIPUSTO.RU (IF EMPTY.RU), PROSTOMASTER (JUST MASTER)).

g) The pursuit of rarity and uniqueness is not always the basis for creating a successful ergonym, since the other criteria turn out to be negative (BIZOVO.RU, ESLIPUSTO.RU (IF EMPTY.RU), POLPOLPOL.RU (FLOOR.RU)). The name Korsety\&Sorocki (Corsets\&Shirts), which has the maximum uniqueness (1.59), is at the same time uninteresting and difficult.

h) Uninteresting domain designations as a name (BIZOVO.RU, POLPOLPOL.RU (FLOOR.RU)). VSEINSTRUMENTI.RU (ALL TOOLS.RU) is rated in a weak positive degree. Zapravka.online (Station.online)repeats the domain designation in form, but it is not.

i) Versatility and uniqueness are opposed in the names of estimation marks (Korsety\&Sorocki (Corsets\&Shirts)) or have similar positive indicators (AIR-WATER, LINZI-TUT (LENSES HERE)).

j) It is noted that if education has all positive estimations, then the depth of estimations has close high (NOL-BOL (Zero-Pain), LINZI-TUT (LENSES HERE)) or average indicators, not reaching the maximum indicators compared to other ergonomic composites (COPI.RUS, Nanobanka (Nanobathhouse)). Positively marked language game in the presence of only Russian components in the words LINZI-TUT (LENSES HERE), Nanobanka (Nanobathhouse), as well as in the word
PROSTOMASTER (JUST MASTER) (with the exception of the medium-negative criterion unpleasant).

k) All names with foreign language components are rated as temporary.

1) A multicomponent name is not necessarily difficult to comprehend: HOUSE-DACHA-INTERIOR is rated as simple as opposed to GRUZOPODYEMSPETSTEHNIKA-SIBIR (WEIGHT LIFTING SPECIAL VEHICLES-SIBERIA).

Summarizing the estimation results by the sum of the criteria for each name (See Table 7) revealed an opposition in perception of understandable and incomprehensible ergonyms. Incomprehensible ergonyms are evaluated with a predominance of negative evaluations by other criteria and constitute a separate subgroup within group B previously selected for the experiment.

The maximum positive marks (the sum of the data on the criteria from 13.22 to 11.75 ) were obtained by composites from the group of non-traditional formations: VSEINSTRUMENTI.RU (ALL TOOLS.RU), LINZI-TUT (LENSES HERE) (adhesions), NOL-BOL (Zero-Pain) (rhyme), BA! TUT! (trampoline) (nonlinear blend). All of these entities are decorated only by means of Russian graphics.

The name is COPI.RUS (contamination with grape hybridization) is also highly appreciated, but the combination of two alphabets reduces the estimation indicators $(9,12)$. Then there are words formed on a relatively new, but already productive three-component model with equal components Audit-taxes-law, HOUSEDACHA-INTERIOR (9.04 and 9.02). A similar twocomponent naming with a fused AIR-WATER spelling has a slightly lower score (7.57). The attribute model of the composite formation with the preposition of the determining component (BusinessProfi, HAPPY-IDEAS, Nanobanka (Nanobathhouse)) received similarly high marks $(8.98,8.95,8.21)$. PROSTOMASTER (JUST $M A S T E R$ ) composite (a combination of an unrealized method of adhesion with contamination and grape hybridization), despite creativity, is evaluated with an average intensity $(6,98)$.

The group of Russian names BIZOVO.RU, PROPRO GROUP, Ellyuneslo (Fly Elly), ESLIPUSTO.RU (IF EMPTY.RU) has negative estimations.

Thus, the analysis showed that both subgroups (negatively perceived and positively perceived names) are formed using non-custom models and methods of word formation, which indicates the absence of a correlation between emotional estimation and the nontraditional way of education. At the same time, the group of traditional names has only positive estimates of the average depth from 8.98 to 6.24. Only the "incomprehensible" abbreviation E2E4 is rated negatively -3.63 . In order to further investigate differences in perception, let us designate the positivelycharacterized composites as Group A1, negatively Group B1. 


\subsection{Association experiment data}

As a result of conducting an association experiment, 3654 reactions were received from 126 questionnaires for 29 names. For each name, association areas (AA) are compiled, the core and periphery are identified, and a semantic gestalt is constructed, and the prevailing reaction types are defined. Let us give an example of a gestalt for nei Aytibay (ITbuy) (CD, DVD store).

Semantic gestalt association area " Aytibay (ITbuy) ":

1. Computer (6); comp (3); PC; computers; computer repair; computer store; computer company; computer shop; if the computer broke; equipment; phone; program; byte (2). The 1st semantic zone is computers.

2. IT (4); IT company (3); Aichi; IT technologies; the king of IT; Ayti must be written it, otherwise it looks like a site with drugs; ITbuy; information company (2); computer science; information site. The 2nd semantic zone is information technology.

3. Babay (3); ah babay. The 3rd semantic zone is babay.

4. Buying a computer; computer, buy; buy a computer; buy information technology; anti purchase; sell something; shop (2); dns; digital store; electronics store; hardware store; company; Group; club. The 4th semantic zone is purchase.

5. The Internet; Internet term; mb internet; online store. The 5th semantic zone is the Internet.

6. Kazakh (2); something Kazakh; Kazakh company; Kazakhstan; Kazybek; Kazakh?; Kyrgyzstan. The 6th semantic zone is an Asian name.

7. Do not sleep (2). The 7th semantic zone is sleep.

8. Aybolit; pharmacy. The 8th semantic zone is treatment.

9. Against; anti purchase; antihipe (3). The 9th semantic zone is against.

10. In addition to these reactions, the estimated reactions are clearly distinguished. Negative reactions are represented by options: it is not clear (2); complex (2); who knows (2); yes, who knows, did not understand); what; cheap. Positive reactions are ridiculous; clearly; good; interesting. The 10th semantic zone is an estimation.

Reactions to the phonetic appearance of the second component include: babay (3); ah babay; do not sleep; at first - aybolit. Phonetic reactions are implemented in semantic zones $6,7,8$ and 9 .

Thus, the analysis of semantic zones and types of reactions allows us to conclude that the name is perceived by respondents as incomprehensible (reactions with seme 'unclear' - 8\%; phonetic reactions $13.9 \%$ ). Particularly incomprehensible is the second component Bay (from the English buy), also falsely interpreted as 'sell'. So, the name Aytibay (ITbuy) is a hardware and computer related store designed for programmers and IT people. The structure of the AA indicates the formation of stable links of the stimulus and reactions: a pronounced large nucleus (reactions with a rank higher than 2 and correlated with them - 43\%) with the near periphery (rank $2-32 \%$ ), fewer reactions of the periphery $(25 \%)$. In the core of the described AA, three leading types of reactions are found: semantic proper, deployment reactions, and explanations. For the near and far periphery, estimation reactions and self-associative.

Based on the analysis of association areas and semantic gestalts, differences were found in the association areas of understandable and incomprehensible names concerning the prevailing types of reactions, composition and number of semantic zones; as well as their correlation type of activity of the analyzed companies.

Semantic zones for the group of understandable names correspond to the profile of the company activity and, as a rule, belong to the same thematic group. For incomprehensible names, the field core is formed by lower-order echolalia reactions or phonetic reactions.

The incomprehensibility and unusualness in perception are also realized in reaction-explanations, when respondents in real-time mode try to comprehend the unusual combination of components, structure and form of content presentation (foreign language components, transliteration), giving detailed interpretations of the names.

Mixed reactions, combining estimation and explanation, are present in the periphery of the association areas of those words, the scope of which affects the personally important areas of activity of companies. Estimated reactions characterize both the name and the intended company activity.

In each of the AA, estimation and reflection reactions were identified about the linguistic phenomena themselves (models and components). Estimation reactions make up a significant part of the analyzed AA (8-15\%). The poles of the assessment of each naming range from positive to sharply negative and emotional, which confirms the perception data of the receptive experiment and explains the low depth of estimations on the scales by different poles of estimations.

Reflection in the perception of names is manifested in the dialogue mode of reactions for incomprehensible names (reactions with a question) and a significant number of reactions to the structure for ergonymic composites formed according to unconventional models.

\section{Conclusion}

So, according to the receptive experiment data, the name, which is estimated by the recipients in the positive part on most scales, is successful, while the motives, functions and goals of the ergonym, different for standard and non-standard names, incorporated at the generation stage, are realized with the help of clear means of meaning for native speaker of Russian. To assess the success of an ergonym, the following 12 scales (in descending order of importance) are the most important, according to the experts who carried out the selection of scales for the experiment: incomprehensible - understandable, abstract - concrete, useless - useful, deceitful - honest, inappropriate - acceptable, inappropriate - relevant, difficult - simple, ordinary unique, rare - frequent, unpleasant - pleasant, uninteresting - interesting, temporary - universal. 
These criteria are consistent with the principles of naming, influencing the generation of the word.

An analysis of the perception of names according to the data of an association experiment led to the conclusion that composites are successful ergonyms, the AA of which, according to the association analysis results, they contain semantic zones corresponding to the profile of the company activity and do not reveal sharply negative assessments and reactions associated with incomprehensibility.

\section{References}

1. G. Charmesson, Brand: how to create a name that will bring millions (St. Petersburg, Peter, 2000)

2. V. Epaneshnikov, My Naim is. About brand names, Advertising industry. Retrieved from: http://www.advertology.ru/article20411.htm

3. A. Wheeller, Brand Identity. Guide to creating, promoting and supporting strong brands (Moscow: Alpina Publishers, 2009)

4. R. Priyanka, AIDA Marketing Communication Model: Stimulating a purchase decision in the minds of the consumers through a linear progression of steps, Int. J. of Multidisciplinary Res. in Social Management, 1, 37-44 (2013)

5. D. Vakratsas, How Advertising Works: What Do We Really Know? J. of Marketing, 1 (1999)

6. E.Ch. Osgood, G. Suci, P. Tannenbaum, The Measurement of Meaning (University of Illinois Press, 1957)

7. M.V. Zakharova-Sarovskaya, O.V. Dubkova, Specificity of perception of complex words in typologically different and genealogically unrelated languages (by the material of firm names in Russian and Chinese), Space of language and languages of spaces, Philology and culture, 182-211 (2017)

8. T.G. Sadykov, Municipal budgets under conditions of economic crises in Russia, SHS Web of Conf. (CILDIAH-2018 - Current Issues of Linguistics and Didactics: The Interdisciplinary Approach in Humanities and Social Sci.), 50, pp. 1-3 (2018)

9. A.I. Khakimova, Diachronic Analysis of English Syntax in Relation to Newspaper Style, SHS Web of Conf. (CILDIAH-2018 - Current Issues of Linguistics and Didactics: The Interdisciplinary Approach in Humanities and Social Sci.), 50, pp. 1-4 (2018)

10. E.R. Vasilyeva, Regional and ethnocultural specifics for developing intercultural and lingua-cultural competences: the pedagogical strategy, SHS Web of Conf. (CILDIAH-2018 - Current Issues of Linguistics and Didactics: The Interdisciplinary Approach in Humanities and Social Sci.), 50, pp. 1-4 (2018) 